\title{
Arterial fistula between the left internal mammary artery and left pulmonary artery
}

\author{
R PILLAI, A MITCHELL, JW JACKSON
}

From Harefield Hospital, Harefield, Middlesex

Systemic artery to pulmonary artery fistula is uncommon and is usually associated with pulmonary sequestration. Eleven cases of internal mammary to pulmonary artery fistula have been reported. ${ }^{1-5}$ It may be present at any age, usually as a continuous murmur at the left sternal edge which may mimic the murmur of a patent ductus arteriosus or a coronary artery aneurysm. It is commonly found in young adults. The natural history and progress of such a fistula is not known as the majority of reported cases have been managed surgically.

\section{Case report}

A 26-year-old man of Asian origin was investigated for a continuous murmur at the left sternal edge. He had been under chest clinic surveillance for abnormal shadowing in the right upper lobe for four years, with a presumed diagnosis of pulmonary tuberculosis, and was treated with a course of anti-tuberculosis chemotherapy. On his most recent visit, a murmur was noted. He was otherwise fit and had no major illnesses in the past.

On examination he was of slight build and had a moder-

Address for reprint requests: J Jackson FRCS, Harefield Hospital, Harefield, Middlesex UB9 6JH. ate degree of pectus excavatum. He was not clinically anaemic and there was no finger clubbing or cyanosis. The pulse was regular and all peripheral pulses were present and normal. The blood pressure was $110 / 80 \mathrm{~mm} \mathrm{Hg}$ in both arms. There was a continuous murmur at the left sternal edge related to the second, third, and fourth intercostal spaces. The breath sounds were normal. The ECG showed sinus rhythm with right bundle branch block. The chest radiograph showed changes suggestive of previous tuberculosis in the right upper lobe. All other routine investigations were normal.

Left heart studies showed no ventricular septal defect, a normal aortic valve, and normal coronary arteries. Aortic root injections showed no patent ductus arteriosus, but branches of the left pulmonary artery were seen to fill from the left internal mammary artery. Selective cannulation of the left internal mammary artery (figure) confirmed that there was a communication between a branch of this systemic artery and branches of the pulmonary artery to the left upper lobe. This communication was deemed to be sufficiently large to warrant surgical closure.

At thoracotomy the lung was free and deflated easily to reveal a vessel, the size of a radial artery, arising from the left internal mammary artery, and communicating with a cluster of vessels lying on the surface of the anterior segment of the left upper lobe. There was a palpable thrill in

Fig 1a

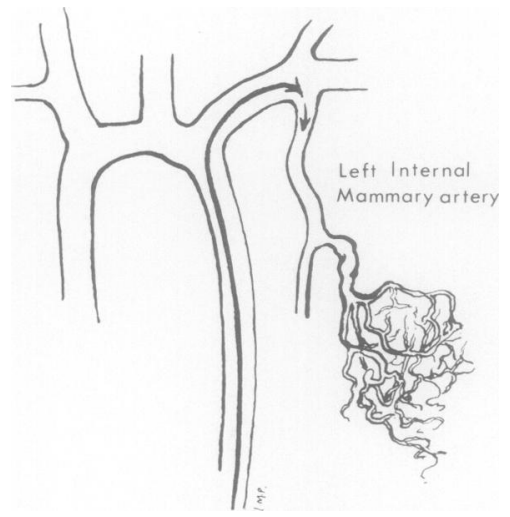

Figure Antero-posterior (a) and lateral (b-next page) angiograms of the left internal mammary artery fistula, which communicated with a branch of the pulmonary artery to the left upper lobe (with diagrammatic representations). 


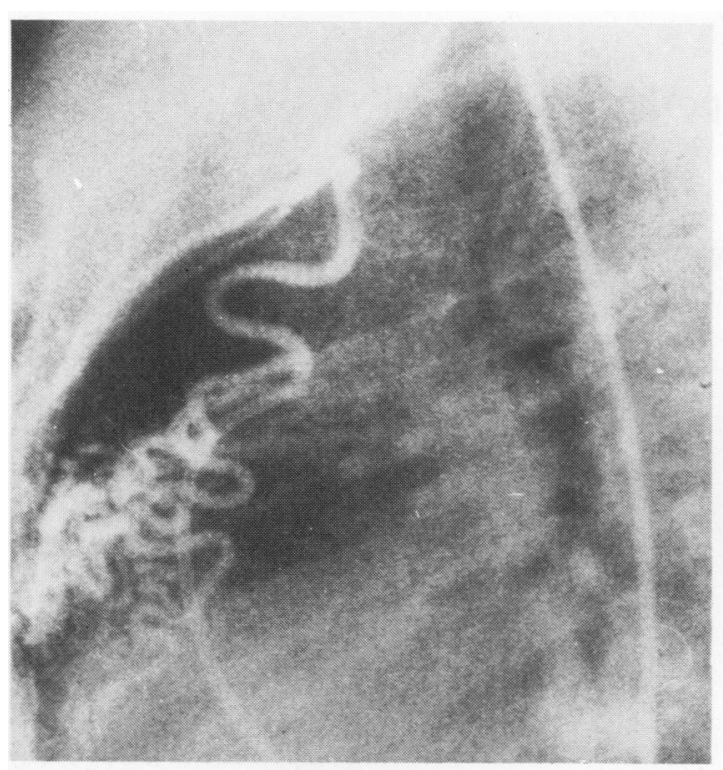

Fig $1 b$

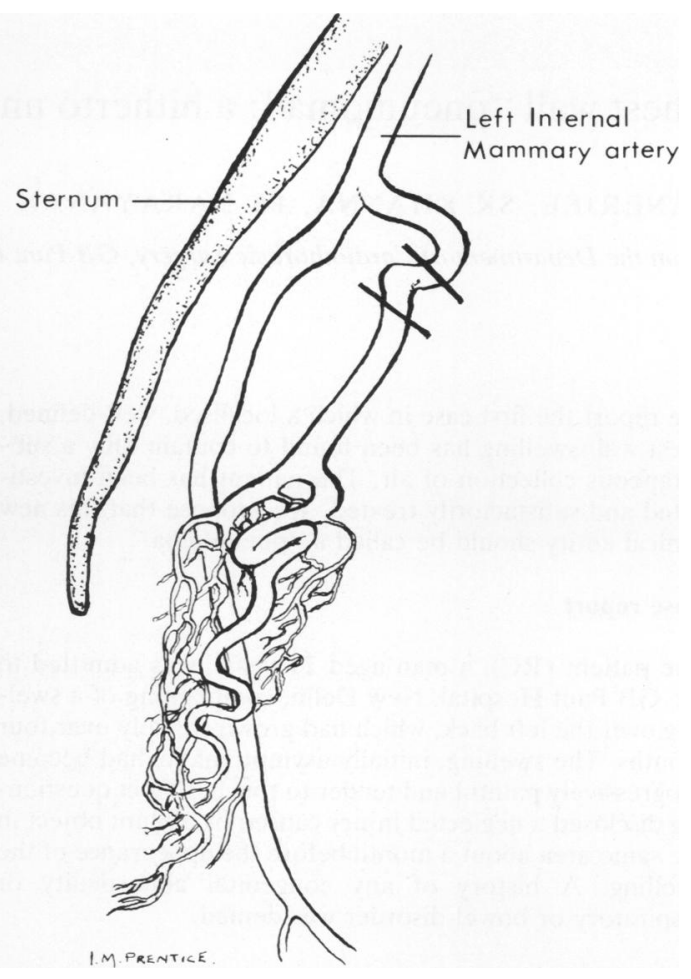

\section{References}

' Hearne SF, Burbank MK. Internal mammary artery-topulmonary artery fistulas. Case report and review of the literature. Circulation 1980;62:1131-5.

${ }^{2}$ Laffay N, Valere P-E, Guerot C, Urbanczyk A, Gentilini M, Tricot $R$. Fistule entre artère systémique et système arteriovenous pulmonaire: à propos d'une observation; revue de la littérature. Ann Med Intern (Paris) 1976;127:437-46.

As in all other reported cases, the discovery of this fistula has been a chance finding. In most cases the fistula must have existed from birth. Its presentation in adult life suggests that it increases in size with age.

Surgery was advised because this abnormality must carry all the risks of any arteriovenous or angiomatous abnormality-for example, progressive increase in size, risk of infection, and aneurysm formation and right or left heart strain with cardiac failure, haemoptysis, and eventually pulmonary hypertension. 